\title{
Rifalazil and Derivative Compounds Show Potent Efficacy in a Mouse Model of $\boldsymbol{H}$. pylori Colonization
}

\author{
David M. Rothstein, Steve Mullin, Klari Sirokman, Karen L. Söndergaard, \\ Starrla Johnson, Judith K. Gwathmey, John van Duzer, Christopher K. Murphy
}

Received: February 16, 2008 / Accepted: July 26, 2008

(C) Japan Antibiotics Research Association

\begin{abstract}
The rifamycin rifalazil (RFZ), and derivatives (NCEs) were efficacious in a mouse model of Helicobacter pylori colonization. Select NCEs were more active in vitro and showed greater efficacy than RFZ. A systemic component contributes to efficacy.
\end{abstract}

Keywords rifalazil, rifamycin, Helicobacter, gastric ulcer disease, efficacy

\section{Introduction}

Infection of the stomach lining with Helicobacter pylori causes gastritis, peptic ulcer disease, and is associated with an increased incidence of gastric adenocarcinoma. In infected individuals, proton pump inhibitors (PPI) provide symptomatic relief and promote healing of benign lesions. However, eradication of this organism by antibacterial therapy is necessary to cure patients [1]. The present regimens for the treatment of $H$. pylori are triple and quadruple therapy with two antibiotics and a proton pump inhibitor and/or bismuth sulfate for up to two weeks [2, 3]. Of the $50 \%$ of patients who report side effects from these treatments, approximately one-fifth discontinue treatment [4]. Although oral antibiotics have been effective in eradicating $H$. pylori, resistance to one or more of the commonly used agents is of growing concern. The rates of resistance range from 5.0 to $40 \%$, and antibiotic resistance in $H$. pylori is associated with initial treatment failure and recurrence of infection $[4 \sim 6]$.

D. M. Rothstein (Corresponding author), S. Mullin, J. van Duzer, C. K. Murphy: ActivBiotics, Inc., 107 Cedar Street, Lexington, MA 02421, E-mail: drothstein@rcn.com
The rifamycin rifabutin has been reported to be an effective component of multiple drug therapy for the treatment of recalcitrant cases of peptic ulcer disease that were failures of first-line therapies [7, 8]. Rifalazil (RFZ), also known as KRM-1648 or ABI-1648 [8], has been shown to have very potent in vitro activity against $H$.

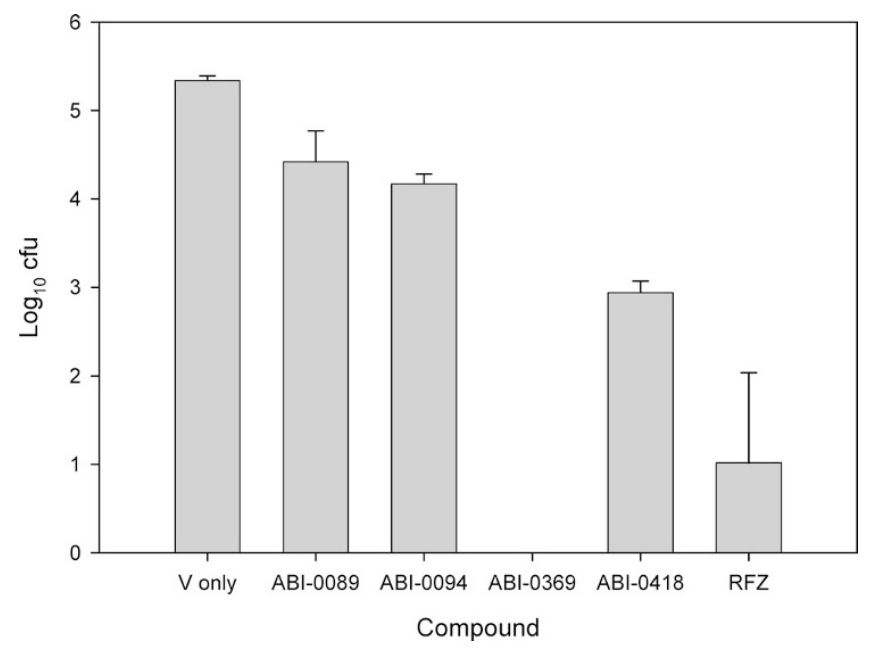

Fig. 1 Screening compounds for efficacy in the mouse model of $H$. pylori infection.

Each compound, ABI-0089, ABI-0094, ABI-0369, ABI-0418, and RFZ, were dosed at $4.0 \mathrm{mg} / \mathrm{kg}$ BID PO for 7 days to 3 mice, stomachs were harvested and homogenized 12 hours after the last dose, and the titer was compared to mice administered vehicle only (designated "V only"). Standard error is indicated by error bars. Treatment with ABI-0369 resulted in bacterial titers that were below the detectable level.

K. Sirokman, K. L. Söndergaard, S. Johnson, J. K. Gwathmey: Gwathmey Inc., 763 Concord Ave. Bldg E, Cambridge, MA 02138 
pylori, with an $\mathrm{MIC}_{90}$ of $0.008 \mu \mathrm{g} / \mathrm{ml}$ [9]. Therefore, it seemed appropriate to test RFZ and derivative compounds (new chemical entities; NCEs; Fig. 1) for both in vitro antibacterial activity and in vivo efficacy using an experimental mouse model of $H$. pylori colonization [10].

\section{Materials and Methods}

\section{Susceptibility Testing}

MIC testing of RFZ and NCEs was performed using an agar dilution method with strain H. pylori ATCC 43504 in accordance with the Clinical Standards Laboratory Institute. Compounds were first dissolved in 100\% DMSO at $1.0 \mathrm{mg} / \mathrm{ml}$, and then diluted into Brucella Agar (Difco) with $5.0 \%$ defibrinated sheep blood (aged $>2$ weeks; Remel), and poured into culture plates. After inoculation with $2.0 \mu \mathrm{l}$ of a $0.5 \mathrm{McF}$ arland unit culture of $\mathrm{H}$. pylori, plates were incubated for 3 days at $37^{\circ} \mathrm{C} / 5.0 \% \mathrm{CO}_{2}$ and $100 \%$ humidity.

\section{Screening NCEs for Efficacy}

Efficacy was determined by utilizing a model in which $\mathrm{C} 57$ $\mathrm{Bl} / 6$ mice were infected for two consecutive days with $10^{7} \mathrm{cfu}$ of $H$. pylori strain SS1, and the infection was allowed to progress for at least one week [10, 11]. Animals were then treated twice daily (BID) for 7 days. Doses for screening were $4.0 \mathrm{mg} / \mathrm{kg}$ of RFZ or NCE, or $50 \mathrm{mg} / \mathrm{kg}$ of amoxicillin (AMX), all delivered by oral gavage (PO) to groups consisting of three animals. Stomachs were harvested 12 hours after the last dose of antibiotic, or for control infected animals, 12 hours after the last dose of vehicle. H. pylori was detected from the stomachs by incubating dilutions of stomach homogenates on plates containing agar medium described above, except that the medium contained Skirrow's supplement $(10 \mu \mathrm{g}$ of vancomycin $/ \mathrm{ml}, 2.5 \mathrm{IU}$ of polymyxin $\mathrm{B} / \mathrm{ml}$, and $5.0 \mu \mathrm{g}$ of trimethoprim/ml; Oxoid Ltd.). Antibacterials were dosed after making the appropriate stock solution in DMSO, and diluting $1 / 10$ by volume into Dissolution Solution $(5.0 \%$ Etocas $35 \mathrm{NF}$ grade [Croda, Inc., Edison, N.J.], $0.9 \% \mathrm{NaCl}$, and $0.1 \mathrm{mM} \mathrm{Na}_{2} \mathrm{HPO}_{4}, \mathrm{pH} 7.4$ ).

\section{Comparing Efficacy of Antibacterials}

RFZ or NCEs were further challenged by testing groups of 5 mice, all dosed at $4.0 \mathrm{mg} / \mathrm{kg}$ BID PO as described above, and by varying the treatment time from 1 to 7 days as indicated, using the same method of $H$. pylori detection as outlined above.

\section{Testing for a Systemic Component of Efficacy}

Groups of 5 mice were treated with RFZ for 3 days, either BID PO, or once daily dosing by intraperitoneal injection (IP). Doses varied from 0.5 to $24 \mathrm{mg} / \mathrm{kg}$ as indicated, and the vehicle for dosing solutions was 33 parts by volume of water and 15 parts by volume of Liquid Fill (375 g Etocas 35NF, $4.4 \mathrm{~g}$ pluronic acid F68, $50.8 \mathrm{~g}$ PEG 400, $10.8 \mathrm{ml}$ water).

\section{Results and Discussion}

\section{In Vitro Potency}

In agreement with previously reported results [9, 12], we found the MIC of RFZ to be $0.002 \mu \mathrm{g} / \mathrm{ml}$ (Table 1). Certain NCEs, such as ABI-0089 and ABI-0699, were even more active than RFZ against $H$. pylori, with MICs $\geq 0.0005$ $\mu \mathrm{g} / \mathrm{ml}$.

Table 1 Structures, and activities of NCEs and rifalazil against H. pylori ATCC 43504

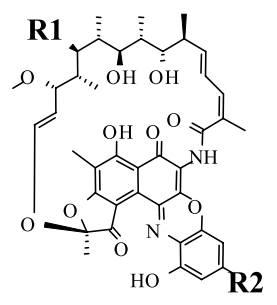

\begin{tabular}{|l|l|l|l|}
\hline Compound & R1 moiety & MIC $(\mu \mathrm{g} / \mathrm{ml})$ \\
\hline Rifalazil & O-acetyl & & 0.002 \\
\hline ABI-0043 & hydroxyl & O-acetyl & \\
\hline ABI-0089 & hydroxyl & \\
\hline ABI-0299 & O-acetyl & \\
\hline ABI-0369 & O-acetyl & \\
\hline ABI-0418 & O-acetyl & \\
\hline O-acetyl &
\end{tabular}




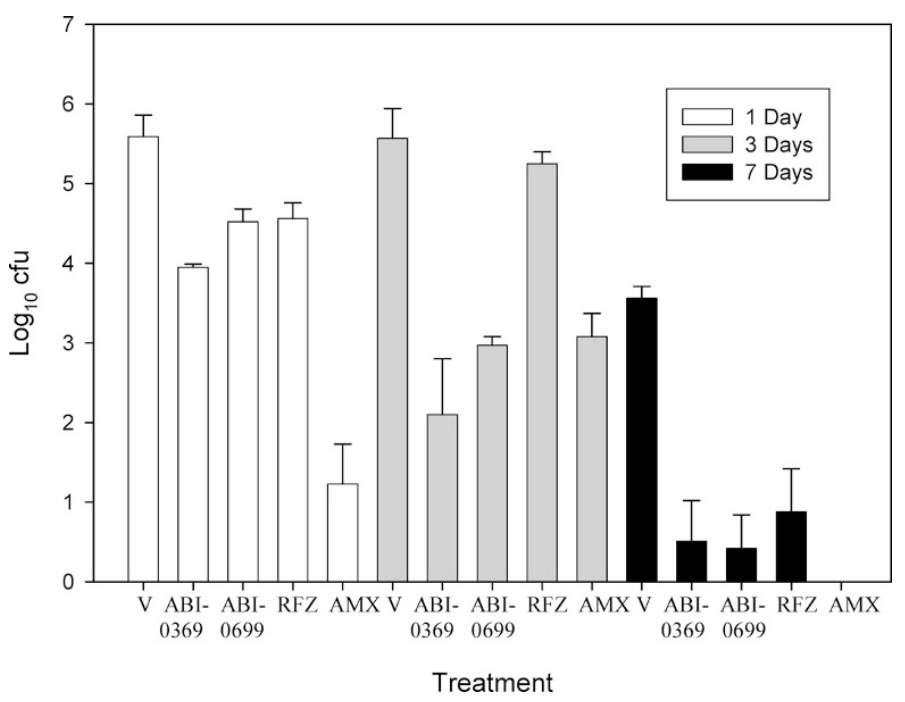

Fig. 2 Efficacy as a function of duration of treatment.

Groups of 5 mice infected with H. pylori were administered vehicle only (V), or $4.0 \mathrm{mg} / \mathrm{kg}$ of ABI-0369, ABI-0699, RFZ, or $50 \mathrm{mg} / \mathrm{kg}$ of AMX, BID PO, for 1,3 , or 7 days as indicated. Standard error is indicated by error bars.

\section{Screening for Efficacy by 7 Day Treatment}

As shown in Fig. 1, the average titer of bacteria in rifalaziltreated animals was reduced multiple log units. For NCEs, ABI-0369 showed greater efficacy per $4.0 \mathrm{mg} / \mathrm{kg}$ dose than ABI-0418, ABI-0094, and ABI-0089. Compounds ABI0299 and ABI-0043 appeared to be less efficacious (data not shown). ABI-0369 was equal to or superior to rifalazil in effect per dose.

\section{Efficacy as a Function of Treatment Time}

The duration of treatment and efficacy was examined for RFZ, ABI-0369 and ABI-699 (Fig. 2). For all compounds, delivered as described above at a dose of $4.0 \mathrm{mg} / \mathrm{kg}$, there was a trend towards efficacy after 1 day, although longer treatment times generally resulted in significant drops in bacterial titer. At 7 days of treatment, both ABI-0369 and ABI-0699 showed efficacy superior to that of RFZ, and roughly equivalent to that of $50 \mathrm{mg} / \mathrm{kg}$ AMX. It is possible, however, that the infection had started to abate in 7 days in animals exposed only to the vehicle, which should be considered when evaluating the efficacy of ABI-0369, ABI0699, RFX, and AMX. The fact that ABI-0369, ABI-0699, and AMX also showed greater efficacy after 3 days of treatment supports the conclusion that these compounds were more efficacious than RFZ (Fig. 2).

\section{Determining if There is a Systemic Component to Efficacy}

It is interesting that there was not a strict correlation of activity and efficacy for NCEs and RFZ. If the predominant

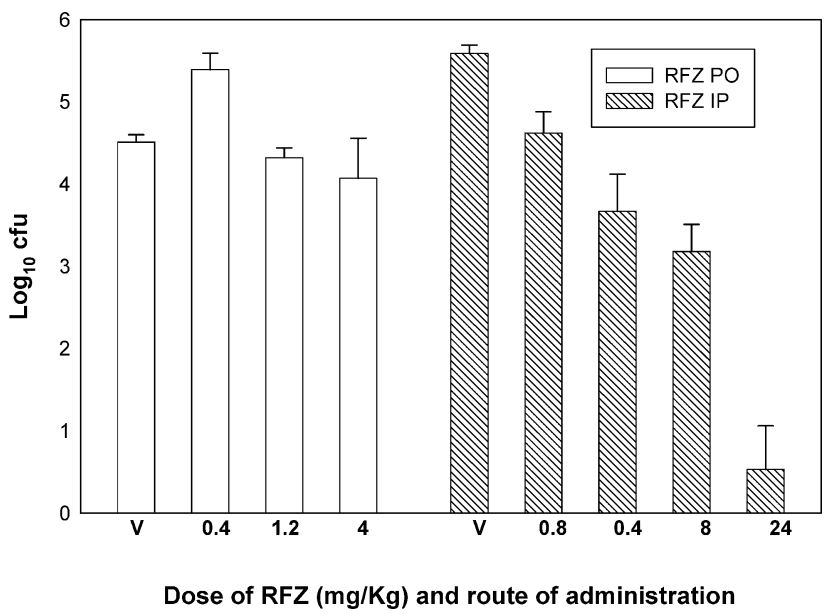

Fig. 3 Survival of H. pylori in the mouse model following $\mathrm{PO}$ and IP administration of rifalazil.

Groups of 5 mice were administered vehicle only (V) or RFZ either twice a day orally (PO), or once daily by intraperitoneal injection (IP), for 7 days at the doses indicated underneath each bar $(\mathrm{mg} / \mathrm{kg})$. Standard error is indicated by error bars.

component of efficacy was the topical exposure upon PO delivery, then it might be expected that activity would closely parallel efficacy. However, some of the most active compounds, such as ABI-0089, performed poorly compared with RFZ, whereas other compounds which weren't as active as ABI-0089 performed better than RFZ (Figs. 1 3). It does not appear that differences in stability of compounds could account for this difference (data not 
shown). A more plausible explanation is there could be a systemic component to efficacy [13]. In order to test if a systemic component contributed to efficacy among the benzoxazinorifamycin family of compounds, RFZ was tested for efficacy when given either as a PO dose twice a day, or by IP administration once daily, based on the idea that IP administration would eliminate the topical exposure of RFZ. As shown in Fig. 3, RFZ delivered systemically resulted in clear efficacy when 24 or $8.0 \mathrm{mg} / \mathrm{kg}$ was delivered IP just once a day, as opposed to a weaker response when $4.0 \mathrm{mg} / \mathrm{kg}$ was delivered PO BID. From the dose-response profile of Fig. 3, it appears that there is a systemic component that contributes to efficacy. It is very possible, therefore, that differences between NCEs result from pharmacokinetic differences among these compounds $[14,15]$. These results are in agreement with studies which indicate that both topical and a systemic component must be considered in efficacy in eradicating $H$. pylori [16].

The potent efficacy of RFZ and the other benzoxazinorifamycins in the mouse colonization model demonstrate their potential as therapeutic agents in the treatment of gastric ulcer disease involving $H$. pylori. The determination of blood levels following oral and IP administration could provide important information in explaining the superior efficacy of ABI-0369 and ABI0699 when compared with RFZ, and could elucidate the importance of the suystemic component in the efficacy of benzoxaminorifamycins against $H$. pylori.

\section{References}

1. Atherton JC et al. Helicobacter pylori Infections. In Harrison's Principles of Internal Medicine-15th edition, Ed., Braunwald E. et al., pp. 960-963, New York, McGrawHill (2001)

2. Howden CW, Hunt RH. Guidelines for the management of Helicobacter pylori infection. Am J Gastroenterol 93: 2330-2338 (1998)

3. Suerbaum S, Michetti P. Helicobacter Pylori Infection. N Engl J Med 347: 1175-1186 (2002)

4. de Boer WA, Tytgat GNJ. Treatment of Helicobacter pylori infection. British Med J 320: 31-34 (2000)

5. McMahon BJT, Hennessy W, Bensler JM, Bruden DL, Parkinson AJ, Morris JM, Hurlburt DA, Bruce MG, Sacco F, Butler JC. The relationship among previous antimicrobial use, antimicrobial resistance, and treatment outcomes for Helicobacter pylori infections. Ann of Int Med 139:
463-469 (2003)

6. Wong WM, Gu O, Wang WH, Fung FM, Berg DE, Lai KC, Xia HH, Hu WH, Chan CK, Chan AO, Yuen MF, Hui CK, Lam SK, Wong BC. Effects of primary metronidazole and clarithromycin resistance to Helicobacter pylori on omeprazole, metronidazole, and clarithromycin tripletherapy regimen in a region with high rates of metronidazole resistance. Clin Inf Dis 37: 882-889 (2003)

7. Gisbert JP, Pajares JM. Review article: Helicobacter pylori "rescue" regimen when proton pump inhibitor-based triple therapies fail. Aliment Pharmacol Ther 16: 1047-1057 (2002)

8. Perri F, Festa V, Clemente R, Villani MR, Quitadamo M, Caruso N, Bergoli ML, Andriulli A. Randomized study of two "rescue" therapies for Helicobacter pylori-infected patients after failure of standard triple therapies. Am J Gastroenterol 96: 58-62 (2001)

9. Akada JK, Shirai M, Fujii K, Okita K, Nakazawa T. In vitro anti-Helicobacter pylori activities of new rifamycin derivatives, KRM-1648 and KRM-1657. Antimicrob Agents Chemother 43: 1072-1076 (1999)

10. Eaton KA, Kersulyte D, Mefford M, Danon SJ, Krakowka S, Berg DE. Role of Helicobacter pylori cag region genes in colonization and gastritis in two animal models. Infect Immun 69: 2902-2908 (2001)

11. Lee A, O-Rourke J, Corazon de Ungria M, Robertson B, Daskalopoulos G, Dixon MF. A standardized mouse model of Helicobacter pylori infection; introducing the Sydney strain. Gastroenterol 112: 1386-1397 (1997)

12. Heep M, Lehn N, Branstatter B, Rieger U, Senzenberger S, Wehrl W. Detection of rifabutin resistance and association of rpoB mutations with resistance to four rifamycin derivatives in Helicobacter pylori. Eur J Clin Microbiol Infect Dis 21: 143-145 (2002)

13. Goddard AF. Review article: factors influencing antibiotic transfer across the gastric mucosa. Aliment Pharmacol Ther 12: 1175-1184 (1998)

14. Rothstein DM, Farquhar RS, Sirokman K, Sondergaard KL, Hazlett C, Doye AA, Gwathmey JK, Mullin S, van Duzer J, Murphy CK. Efficacy of novel rifamycin derivatives against rifamycin-sensitive and -resistant Staphylococcus aureus in murine models of infection. Antimicrob Agents Chemother 50: 3658-3664 (2006)

15. Rothstein DM, Shalish C, Murphy CK, Sternlicht A, Campbell LA. Development potential of rifalazil and other benzoxazinorifamycins. Expert Opin Investig Drugs 15: 603-623 (2006)

16. Goddard AF. Review article: factors influencing antibiotic transfer across the gastric mucosa. Aliment Pharmacol Ther 12: 1175-1184 (1998) 